\title{
Lengua y sociedad: \\ El que no tiene de inga tiene de mandinga
}

\author{
Augusto Alcocer Martínez \\ Universidad Nacional Mayor de San Marcos
}

Para J. L. Rivarola

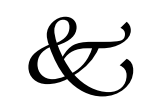

\begin{abstract}
Restmen
El presente artíarlo explora tanto lingüística camo aulturalmente el dicho Ell que no tiene de inga tiene de mandinga. uno de sus propósitos es determinar su origen y establecer el momento en que fue empleado en el perú por primera vez. También se propone demostrar que la unidad sintáctica en cuestión no es un refrán, adagio, proverbio o frase célebre, sino un dicho. Finalmente, se demuestra que la expresión referida no fue generada en ciranstancias vinculadas con nuestro devenir cultural y que no fue Ricardo Palma su creador como se suponía hasta hoy. El estudio utiliza materiales provenientes de la literatura y la historia y trabaja con fichas que sirven cano sqporte para la demostración de sus hipótesis.
\end{abstract}

Palabras claves: El que no tiene de inga tiene de mandinga, dicta, delimitación lexicográfica, uso social.

\section{Introducción}

T a paciente tarea de reunir materiales para validar documenta-

Lriamente el uso de medio millar de entradas léxicas ofrecidas en Neologismos y Americanismos (Ricardo Palma: 1899), motivo central de una investigación personal, nos condujo, de modo impensado, a la pretérita frase Ell que no tiene de inga tiene de mandinga. 
La amplitud de miras a que se sometió la lectura y 'despojo' , tanto de obras de literatura, historia, ensayo como multiplicidad de fuentes peruanas destinadas a otra clase de trabajo, generó que se transcribieran numerosas fichas, algunas de las cuales, expuestas a escrutinio, fueron constituyendo, no dostante, un conpus diferenciado que ha servido de base para poder pergeñar el presente artículo.

\section{Uso actual de la frase entre la clase culta}

Una de las expresiones populares empleada con más asicuidad por muestra gente para señalar la colisión de sangres en el perú de nuestros días y que compite sabrosamente con la modema cita "todas las sangres", también étnico-cultural, es El que no tiene de inga tiene de mandinga.

Escritores de elevada representación en la historia, sociología y en el ensayo como Roberto Mc-Lean y Estenós (1948: 133), Denys Cuche (1975: 108), Franklin Pease G.Y. (1993: 20),Wilfredo Kapsoli (1996: 22) u Osvaldo Holguín Callo (2000: 129) y otros intelectuales conceden en la práctica, el derecho de propiedad de la frase a Ricardo Palma.

Renombrados autores y periodistas de los medios masivos de información escritos y hablados, quizás por considerarlo dovio (alusión al famoso tradicionista) o atendiendo al significado de sus propias intuiciones -hace siglos que la frase ha ingresado al dominio públicose abstienen de señalar autoría: Max Hemández y Roger Rumrril (1994: 35) , José Carlos Luciano (1995: 53) ; Jorge Paredes y Juan Velit (1999: 89) , Luis Delgado Aparicio (2000:29) y el caso que a nadie extraña, flor de vitalidad, la primera plana dominical, columa "Buenos Días" de EI Comercio -el diario con mayor lectoría del Perú- del 27-V-2003. En esta relación es preciso incluir el nombre de Rubén Vargas Ugarte (1968: 75) especialista en historia colonial, y también recordar que en el año de 1979 el crítico literario Estuardo Núñez propuso, en el seno de la Comisión de Lexicografía de la Academia Peruana de la Lengua, su proyecto de definición de 'mandinga' y añadió con la cautela de rigor, la necesidad de indagar por más pruebas sobre el uso de la expresión El que no tiene de inga tiene de mandinga. 


\section{Las unidades lexicales múltiples: las citas o frases proverbiales, refrán o adagio y el dicho popular}

Para desarrollar el parágrafo, acudiremos al aporte de dos disciplinas conexas: Ia Lexicología y la Lexicografía. Por consiguiente, las líneas que siguen ofrecerán una visión sintética de las ideas que, sobre el concepto operativo "unidades lexicales múltiples", en adelante ULM, ha desarrollado Ladislav Zgusta (1971: 138-163) , uno de los más prestigiosos cultores de aquellas materias.

Ias UIM se pueden identificar, según Zgusta, mediante el auxilio de nueve criterios. De estos, dos son los que conviene resaltar: el primero postula el principio de sustitución, que plantea que las palabras se relacionan significativamente formando oraciones o frases en las llamadas 'combinaciones libres de palabras', cuyos elementos son sustituibles e intercambiables:

Se arriendan departamentos.

Se pintan departamentos.

Se venden departamentos.

Existen también unidades lingüristicas que, al combinarse entre ellas, constituirán combinaciones fijas, estables, fosilizadas y que expresarán un significado claro, transparente:

Paso a desnivel.

Tarjeta de crédito.

Pasar lavoz.

Se presentan, igualmente, otras agrupaciones fijas, portadoras de un significado lexical que resultará diferente de la suma de los significados de sus elementos constituyentes; es decir, se concibe el significado léxico como un todo que no se deriva absolutamente de sus componentes:

$\begin{array}{ll}\text { Sacolargo } & \text { 'mariob qprimido'. } \\ \text { Papel quemado } & \text { 'hombre casado'. } \\ \text { Hacer el bajo } & \text { 'alcahretear'. }\end{array}$

En estos ejemplos relativos al amor limeño, las ULM, en rigor, combinaciones fijas, se ven impedidas de sustituir o permutar algunos de sus elementos componentes básicos por la razón de que se alteraría el significado lexical del conjunto. 
El segundo importante, entre los nueve criterios, anumcia que no todas las combinaciones fijas constituyen ULM porque tienen que cumplir con un requisito fundamental: una UIM debe funcionar sintáctica y onomasiológicamente dentro de la oración (sintagmáticamente) , y en el sistema lexical de una lengua, o lexicón (paradigmáticamente) como una palabra simple:

La mano de dbra para confecciones abunda en Lima.

La industria requiere mano de dora cal i ficada.

Ios costos por mano de dora paral izaron los trabajos.

Por lo expuesto, las combinaciones fijas: llamadas dicta (dichos), citas o frases proverbiales, sentencias o máximas y los refranes o adagios no son ULM por la sencilla explicación de que no cumplen con las dos condiciones acabadas de señalar.

\section{Hacia una explicación de los dicta o dichos}

De entrada, se debe advertir que pasaremos por alto las atendibles especulaciones que, sobre la naturaleza del refrán y frase proverbial, ha realizado Julio Casares (1950: parte III, Cap. II ) . Nos limitaremos a describir el concepto de dicta o dichos contrastándolo con algunos rasgos sémico-formales de aquellos.

El dicho, tal y como lo define la última edición del diccionario académico, cito ad libitum, equivale a "Frase aguda e ingeniosa con que se expresa oralmente -el subrayado es nuestro- un concepto cabal" :

Ver a Jidas calato

Caer (a uno) la quincha
'Ver estrell las a causa de un oblor agubb'.

'Caerle la desgracia'.

El refrán se identifica por su tono sentencioso, didáctico-moralizadbr, como en:

De día beata y de noche gata.

Dios es penuano y nos da la mano.

Estos rasgos faltan en los dichos. En ciertos casos hay puntos de encuentro y confusión, además de repartirse la popularidad, algunos dichos, al igual que muchos refranes, comparten una fisonomía rítmicomusical; dicta o dichos poseídos de cierta artisticidad que circulan de boca en boca y de casa en casa, como en dos siguientes ejemplos (uno de Huánuco y otro de Piura) : 
(Hîbrido hispánico con préstamos quechuas)

Donde hay tacacuy hay cuyacuy 'Donde hay golpes hay cariño' .

La chicha en poto, el 'picau' en mate y la china en petate.

Las citas o frases proverbiales, distintas a los dichos (habla coloquial) , tienen necesaria representación gráfico-visual. Son construcciones extraídas de un texto escrito (literario, histórico o ensayo) que han tenido la fortuna de extenderse, divulgarse y alcanzar tanta notoriedad hasta el punto de hacerse proverbiales. He aquí una famosa cita peninsular:

"..........

¿Mas, que mucho que yo perdido ande

por un engaño tal, pues que sabemos

que nos engaña así la naturaleza?

porque ese cielo azul que todos vemos

No es cielo ni es azul ¡ lástima grande

que no sea verdad tanta belleza!

Lupercio Argensola

Leamos una cita peruana:

".........

Señor Ministro de Salud: ¿Qué hacer?

¡Ah! desgraciadamente, hombres humanos,

Hay, hermanos, muchísimo que hacer" .

césar Vallejo

\section{Delimitación lexicográfica}

De acuerdo con los dictados de la Semántica, Lexicología y Lexicografía teórica, se considera que tanto las formas como los significados de los dicta o dichos, frases proverbiales o citas y los refranes o adagios, incumplen los requisitos esenciales propuestos por Zgusta para caracterizar una ULM, pues aquellas terminologías fraseológicas y paremiológicas no representan el valor y la función de palabra o lexía simple, sino sólo equivalen a oraciones completas. Entonces, por motivos ya doblemente explicados, están impedidas, según mandan los cánones lexicográficos, de incluirse en diccionarios como el oficial o uno de uso descriptivo; así lo estima también el maestro Casares (1950: 197-199), aunque podrían encontrar un 
legítimo lugar en un refranero, un diccicnario de citas y frases célebres, dichos o en un monumental diccionario histórico.

Se han examinado ya las peculiaridades que distinguen a las diferentes unidades pluriverbales; por lo tanto, el camino ha quedado despejado para asignar al dicho la debida ubicación.

Descártense refrán o adagio, sentencia o máxima; también cita o frase proverbial. Los primeros, por su cualidad sentenciosa; de igual modo, los últimos, cuyas fuentes hay que ir a buscarlas en un texto escrito. En consecuencia, queda adscribir Ell que no tiene de inga tiene de mandinga entre los dicta o dichos, tanto por su inconfundible sello popular -autor anónimo- como por su índole coloquial o hablada. Para apoyar el aserto cito a:

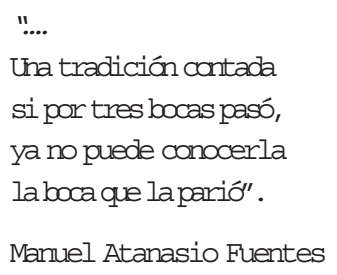

\section{Extensión de uso}

En la Lima actual, El que no tiene de inga tiene de mandinga, además de gozar de vitalidad, es un dicho popular que alude a la mezcla de sangres entre indios, negros, asiáticos y blancos. Previo inicio de un dinámico proceso de cruce de razas; tal vez, el dicho empezó a gestarse en los albores del siglo XVII en que los nativos de la nación mandinga, (pueblos sudaneses residentes en Gambia y ex Guinea francesa) eran enviados al "país de los ingas":

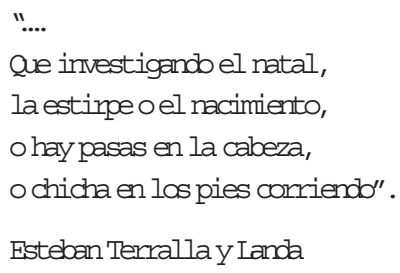

El sabroso dicho, de Lima pasaría primero a Ecuador, H. Toscano Mateus (1953: 413), Justino Comejo (1974: ante prólogo); más tarde 
su radio de dispersión alcanzó en las Antillas a islas como Cuba, A. Santisteban (1997:15 y 156) y Puerto Rico, M. Álvarez Nazario (1961:367). En los tres países se escucha la variante El que no tiene de inga tiene de mandinga. Con parecido significado racial se emplea la frase competidora Ell que no tiene de congo, tiene de carabelí, para señalar en la zona caribeña la presencia de la sangre africana.

\section{De qué sectores sociales procedería el dicho}

La irrupción del capitalismo en América y, por ende, en el Perú significó la entrada, en el siglo XVI, del racismo, debido al proceso de acumulación de capital, que necesitaba mantener al sector explotado de la población controlado económica e ideológicamente. Tras la invasión española, la vida colonial se organizó de acuerdo con un sistema jerárquico socio-racial. La complejidad de las vinculaciones sociales, políticas y económicas durante tres siglos de virreinato estuvieron enmarcadas en un rígido sistema europeo de dominación racial. Los españoles peninsulares, y los criollos después, se reservaron no sólo los más altos cargos burocráticos y mercantiles, sino que se convirtieron en dueños de latifundios; los mestizos, el resto, fueron pequeños propietarios, artesanos, pulperos; los mulatos se dedicaron a eventuales oficios manuales; los indios trabajaron como siervos de la tierra y los negros vivieron la triste condición de esclavas.

De esta realidad, las diferencias raciales my tempranamente sirvieron de base para organizar, de un lado, la sociedad en dos excluyentes estamentos: Ia aristocracia y la plebe, como señala A. Flores Galindo (1984) ; y, por otro lado, para fijar la asimétrica estructura económica del virreinato.

Si lo expuesto configura la gran articulación económico-social de la colonia; entonces hay que preguntarse ¿de qué sectores sociales habría surgido el dicho en los siglos XVII o XVIII?

Teniendo como apoyo las formulaciones históricas y sociológicas de A. Flores Galindo (1984), proponemos sobre el tema dos conjeturas: primero, los peninsulares 'chapetones' consecuentes con el puritanismo de sus creencias religiosas e ideológicas (pureza de sangre) rechazaban la mezcla de las razas y todo tipo de mestizaje, por consiguiente acuñarían la frase para cuestionar el nacimiento de ciertos criollos y 
así denigrarlos, ofenderlos y sacarlos de carrera en la lucha por la vida; y segundo, la estructura piramidal de la sociedad limeña incluía en su base a los mulatos 'palanganas', grupo marginal y contestatario, que soplarían por lo bajo el dicho y lo harían correr a modo de moneda en circulación para denostar y burlarse de la aristocracia.

\section{Algunas referencias a 'mandinga' en la literatura colonial}

El que no tiene de inga tiene de mandinga es innegable producto del habla limeña, creado posiblemente en los primeros siglos coloniales. Se presume que para conocer el origen del dicho hay mucho por investigar aún, pues los archivos coloniales deben esconder un sinnúmero de noticias y sorpresas. A pesar de nuestros empeños, sólo hemos tenido tiempo y humor, aunque escasa fortuna, para rastrear las huellas de la frase en algunas dbras coloniales como: El diario de Lima (1629-1634) , El diente del Pamaso, escrito entre 1683 a 1691; El lazari 710 de ciegas caminantes (1773) , o Lima por dentro y fuera (1797) , de sus respectivos autores Juan Antonio Suardo, Juan del Valle y Caviedes, Concolorcorvo y Esteban Terralla y Landa; en las cuales apenas se encuentran referencias a 'mandinga' (negro) en el segundo de ellos:

"(...)

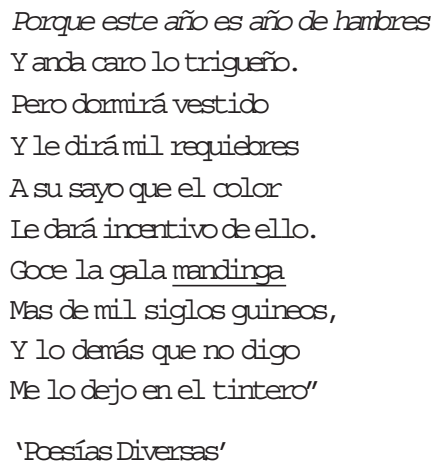

En la tradición 'Mosquita muerta' se introduce 'mandinga' (diablo) en una décima escrita hacia 1724 contra el virrey Marqués de Castelfuerte, y que Palma atribuye a un fraile agustino:

"Ni a descomunión mayor, ni a vestir el sambenito, 
tiene pena ese maldito

endurecido pecador.

mandinga, que es embaidor,

lo sacó de su caldero:

Vino con piel de cordero

Teniéndblo de leán...

Mas ¡chitón, dritón, dritón!"

El año de 1773, Concolorcorvo en las primeras páginas de su Lazarillo menciona 'callejones de matamandinga', para aludir a un conocido barrio de negros ubicado en Abajo el puente (actual avenida Francisco Pizarro) . He aquí un extracto:

"Cierta señorita, añadió, que viviendb en la calle de las Aldabas encargó a un cortejante que vivía a la otra banda del puente (...) que sin perder camino, pasase a la última huerta, que está en los callejones de matamandinga y la trajese un tulipán ..."

concolorcorvo

Lexía que Manuel Ascencio Segura estampó dos veces en su artículo de costumbres El Puente y que apareció por vez primera en el diario la Bolsa en el año de 1841, Segura (1885: 4-5) .

\section{Tempranos registros republicanos del dicho en la tradición oral escrita del español limeño}

La comedia en tres actos 'Un Juguete', cuya acción, según la voluntad de M. A. Segura, transcurre en la Lima del Mariscal Ramón Castilla (1857) fue estrenada en enero de 1858; de modo provisional, sería 'el punto a quo' entre las atestiguaciones documentales que dan cuenta de la famosa frase. El autor costumbrista pone en boca de un personaje vinculado a una familia de la clase media, según Jorge Basadre (1994:123) , Doña Matea, el parlamento:

"....

Esa unión no se hará nunca.

Mi hija no tiene, a Dios gracias,

Ni de inga ni de mandinga,

Ni está tan abarrajada

Para unirse con un hombre 
Que ayer no más tuvo capa;

Y cuya sangre no está,

Como es notorio, my clara".

M. A. Segura (1885: 256)

Dieciséis años después un joven talentoso Ricardo Dávalos y Lissón escribe un artículo de color local '¡Eran beatas!' (1874) , en el cual das mujeres del pueblo, en un diálogo picante, sueltan el dicharacho:

(En la puerta de un templo limeño)

"-Sí, hija, porque tienen cuatro reales, ganados

sabe Dios cámo y en dónde, las consideran y hasta

en la iglesia quieren imponer leyes. ¡Mire usted, no

no pueden esperarse!

¿Por qué somos pobres? Cuidado pues iy mire usted a

quién! Cuando todos tenemos algo de inga o de

mandinga.

- ¡Niña, por Dios! Qué de cosas le has dicho:

¡Y las ha oídb!

- Pues para qué las dije yo, sino para que las oyera, y se fuera bien requemada? (sic) "

R. Dávalos y Lissán

Sigue Abelardo Gamarra (El Tunante), de fecunda colaboración en el periodismo, lo mismo que destacado escritor costumbrista. El autor remite el tema a "una serie de artículos que con el título de 'Recuerdos de un Cronista' escribimos (...) allá por el año 86". Gamarra presenta el dicho popular con una estilística variante verbal:

No hemos heredado la sangre, la religión, las costumbres y la lengua, con la condición de conservarlas íntegras: sin mezcla ni alteración alguna. En materia de sangre, por ejemplo, trabajaremos por españonalizamos ? (sic) ¿No es ya hasta ridícula pretensión dársela de español aquí, donde por la ciranstancia de haber sidb convertido nuestro suelo en lo que tan propiamente llama Samper 'El valle de Josafat de los vivos', fatalmente se dice El que no pende de inga pende de mandinga.

A. Gamarra

Un artículo periodístico 'De medio pelo' publicado anónimamente por el gran tribumo nacional Manuel González Prada en el diario proletario de Lima Los Parias, número 32, febrero de 1907 consigna el tema en cuestión: 
'Quien no tiene de inga tiene de mandinga' asegura un dicho popular; y efectivamente, si escudriñamos el origen de las más empingorotadas familias limeñas, veremos que ninguna deja de contar en su ascendencia un cholo ni un zambo. Nuestras venerabilísimas abuelas y bisabuelas, aunque godas hasta la médula de los huesos, eran cosmopolitas en anor...

M. González Prada

Ismael Portal testifica:

Esto de zambear hase hecho ya manía y unos y otros nos zambeamos de lo lindo sin considerar que 'el que no tiene de inga tiene de mandinga'.

I. Portal

Estuardo Núñez (1974) ha dado a conocer a Marco A. De la Fuente, periodista y escritor, amigo liberteño de Ricardo Palma. Se cree que a través de los contactos intelectuales de éste, llegó a colaborar en la revista madrileña Hojas Selectas, que circuló en España y América y que acogió en sus páginas la tradición "Don Ricardo Palma 'tradicionado' (1919) . En el relato, De la Fuente muestra no sólo su talento literario, sino la buscada prueba:

El viajero llegó y fue capturadb: se llamaba Ricardb Palma (... L La causa por qué se le perseguía, sólo eran sospechas de complicidad en una revolución que se creía próxima a estallar. En aquel tiempo, ser revolucionario no era pecado mortal ni cosa parecida, porque el que no tenía de inga, tenía de mandinga.

M. A. de la Fuente

La presente revista histórica, aún esbozada, concluye con un texto que pertenece a un ya bien entrado siglo Xx:

A la vista de mi cabeza, donde se advierte el noble desarrollo anterior del cráneo -característico de las razas blancas-y de los finos y dorados cabell los que me acompañan aún en mi vejez horaciana, hay motivos para desechar aquella ultrajante afirmación de que 'en América, el que no tiene de inga tiene de mandinga' .

C. Camino Calderón 


\section{9. ¿Ricardo Palma, autor de la frase?}

\subsection{Argumentos a favor}

La fortuna no ha sido esquiva con el Tradicionista porque la gracia, burla y añejo sabor que destila el contenido de la frase encaja al dedillo el estilo narrativo palmiano con el espíritu e idiosincrasia del pueblo limeño:

La tradiciónno es precisamente historia sino relato papular, yya se sabe que para mentiroso el pueblo. Las mías han caído en gracia no porque encamen mucha verdad; sino porque revelan el espíritu y la expresión de las multitudes.

Carta a A. Larco Herrera de 26 -II -1907

Otra variable tributaria de lo arriba señalado, que abona la tesis de atribuir la patemidad y éxito del dicho al autor de las Tradiciones y a su estimable aunque poco vista con detenimiento, obra lexicográfica, la pongo en boca de Palma:

"... consiste en preocuparme de auestiones de gramatiquería y lingüística castellana".

Observación más aplicada efectúa Roy Tanner (2003:159) : Es bien sabido que Ricardo Palma colocó en las tradiciones una plétora de refranes, dichos y frases especiales (... Combinaciones con un rico contenido aultural histórico constituyen una veta filológica ampliamente explotada por Palma.

De lo mencionado se desprende que la armoniosa percepción auditiva de la UIM analizada está en la línea de una práctica que evoca seculares y pegajosos binomios castellanos rimados del tipo:

$$
\begin{array}{ll}
\text { angas-mangas } & \text { ceca-meca } \\
\text { Chana- Juana } & \text { troche-moche }
\end{array}
$$

Los que fueron incorporados entre otros recursos estilísticos a la prosa del Tradicionista. Esta similitud o analogía de efecto acústico en la tradición lingüístico-literaria hispánica y en las Tradiciones peruanas, a nuestro juicio, inclinó la simpatía popular a favor de la autoría de Palma. Es decir, el efecto sonoro podría haber dado un impulso adicional al inga-mandinga. 


\subsection{Argumentos en contra}

Todos los escritos de Palma (las famosas Tradiciones peruanas, las mencionadas, pero poco leídas Tradiciones en salsa verde, las Tradiciones en salsa roja, las que JulioDíaz Falconí (1991) denomina Tradiciones 'olvidadas'; el Epistolario I, y la dora poética completa) que pudieran haberse ocupado del punto, se hallan acordes para ofrecer una contestación negativa.

Otro argumento que descarta la patemidad de Palma sobre la frase es el que llamaremos generacional. Manuel A. Segura nació en el tramo final del periodo colonial, 1805 y recogió el dicho en 1857. En aquel entonces Palma frisaba los 24 años, es decir, andaba en su etapa formativa de escritor y apenas hacía sus primeras armas literarias. Finalmente, hay que apuntar que la crítica especializada indica que las Tradiciones peruanas empezaron a escribirse al rededor de 1860.

En resumen, la afirmación El que no tiene de inga tiene de mandinga, atribuida por muchos peruanos a Ricardo Palma, constituye una adjudicación desacertada.

\section{Conclusiones}

1 Las explicaciones ya formuladas al inicio han demostrado que la frase estudiada se puede caracterizar como un dicho popular.

2 Eventualmente, se ha probado el punto a quo (1857) del dicho, todo lo cual le da a la fecha una aparente antigüedad de 148 años.

3. Los documentos literarios mencionados en el presente artículo prueban concluyentemente que Ricardo Palma, en el periodo republicano, jamás escribió la frase El queno tiene de inga, tiene de mandinga.

\section{Referencias bibliográficas}

ÁLVAREZ NAZARIO, Manuel(1961): El elemento afronegroide en el español de Puerto Rico. Instituto de Cultura Puertorriqueña. San Juan de Puerto Rico.

CAMINO CALDERÓN, Carlos (1925): La Cruz de Santiago (Memorias de un limeño). Talleres Goycochea Hnos, Trujillo. 
CASARES, Julio (1950): Introducción a la lexicografía moderna . Madrid.

CUCHE, Denys (1975): Poder blanco y resistencia negra. INC. Lima.

CUERVO, Rufino José (1987): “Algunas antiguallas del habla hispanoamericana" en Disquisiciones sobre filología castellana, Obras, T. III, Instituto Caro y Cuervo. Bogotá.

DÁVALOS Y LISSÓN, Ricardo (1913): Lima antaño. Librería e imprenta Gil.

DE LA FUENTE, M. (1974): “Palma “tradicionado" en Tradiciones desconocidas. Ediciones PEISA. Lima.

FLORES GALINDO, Alberto (1984): Aristocracia y plebe. Lima 1760-1830. Mosca Azul Editores. Lima.

GAMARRA, Abelardo (El Tunante) (1899): Rasgos de pluma. Víctor Torres editor. Lima.

GONZÁLEZ PRADA, Manuel (1984): "De medio pelo" en Obras, T. II. Vol. 4. Ediciones Copé. Lima.

HOLGUÍN, Oswaldo (2000): Páginas sobre Ricardo Palma. Universidad Ricardo Palma, Lima.

KAPSOLI, Wilfredo (1996): “La identidad nacional”. Universidad y sociedad.IV, 6, pp. 20-28.

MAC LEAN y ESTENÓS (1948): Los negros en el Perú.P.T.C.M. Lima.

PALMA, Ricardo (1899): Recuerdos de España. Imprenta la Industria. Lima

PORTAL , Ismael (1912): Lima de ayer y hoy. Librería e Imprenta Gil. Lima.

SANTISTEBAN, Argelio (1977): El habla popular cubana de hoy. Editorial Ciencias Sociales. La Habana.

SEGURA, Manuel A. (1885): Artículos, poesías y comedias. Carlos Prince editor. Lima.

TANNER, Roy (2003): "Las tradiciones peruanas como foro lingüístico" Revista de la Casa Museo Ricardo Palma, Año III, 3, pp.149-166.

TOSCANO MATEUS, Humberto (1953): El Español en el Ecuador. Revista de Filología. Anejo LXI,CSIC. Madrid.

VARGAS UGARTE, Rubén (1968): Glosario de peruanismos. Lima.

ZGUSTA, Ladislav (1971): Manual of Lexicography. Mouton. The Hague. 